\title{
THE ROLE OF OR IN STRATEGY DEVELOPMENT
}

\author{
RICHARD J. ORMEROD ${ }^{1}$ \\ Warwick Business School \\ Warwick University, United Kingdom
}

\begin{abstract}
Reflecting on the experiences of applying OR approaches in a variety of contexts, the paper draws attention to some of the ways that OR can be brought to bear on strategic issues. Perhaps most frequently the strategic contribution derives from projects aimed at operational issues which have strategic implications. The paper argues that $O R$ practitioners cannot expect to be given a role in strategy questions as of right, nor is there an "OR solution" to strategic questions. However, many OR scientists do have the skills, approaches and methods that can be usefully deployed, if they develop the confidence to do so.
\end{abstract}

\section{INTRODUCTION}

In this paper I want to draw attention to the important role that OR can play in strategy development. I believe that strategy does not always receive the attention it deserves at OR conferences, in OR academia and where it really matters in OR groups. Partly this is because operations have quite naturally been the traditional focus of OR projects. Partly this reflects the difficulty of gaining access at the highest levels. There is also competition from other groups within the organisation, including strategy groups themselves who may wish to retain ownership of the problems. Even if OR groups are involved in strategic issues they may well be reluctant to publish their results, given the sensitivities that will be involved. This in part explains the scarcity of publications and papers at conferences on strategic applications. There is a need therefore to ensure that a focus is retained on

\footnotetext{
${ }^{1}$ Keynote Address at the 1993 Conference of the OR Society of South Africa, University of Natal, Pietermaritzburg
} 
strategic issues within the OR community and I would like strategy to be a major theme of this conference. I will begin by relating my early experiences as an OR scientist.

http://orion.journals.ac.za/

\section{OR APPLIED TO OPERATIONS}

Like most practitioners, I started my career in OR at the 'coal face' of my workplace. In my case this was literally true, crawling on my hands and knees through the machinery of the coal face trying to understand what it was all about. In 1974 I had joined the Operational Research Executive (ORE) of the National Coal Board (NCB), an organisation which will be known to many of you as the largest and arguably the most successful OR group in the UK at the time. There were 130 or so OR scientists employed on a great variety of projects. I will describe my first project in some detail to illustrate how such projects arose, and evolved.

I was located in the Yorkshire coalfield with the task of providing an OR service to the North Yorkshire Area, one of the 12 production areas of the NCB. Projects arose out of past successful work in North Yorkshire, successful work in other areas which was thought to be applicable and discussions with managers about their problems and how OR might assist.

However, these choices took place in the context of a good deal of thought and discussion about the problems of the industry as a whole and where OR, a scarce resource, could be deployed most effectively. Headquarter groups were established to address the important areas that had been identified, to develop methods that could be deployed throughout the production Areas and to support the work of the Area OR teams.

One such research area was the provisioning of equipment, a major capital expenditure item accounting for $70-80 \%$ of the Boards fixed assets. By far the largest proportion of expenditure on equipment was for the machinery on the production faces. Within that total the lion's share was spent on powered supports to control the geological strata along the coal face. Powered supports are hydraulic jacks that maintain the gap between the roof and the floor which 


\section{The Powered Support Provisioning Cycle}

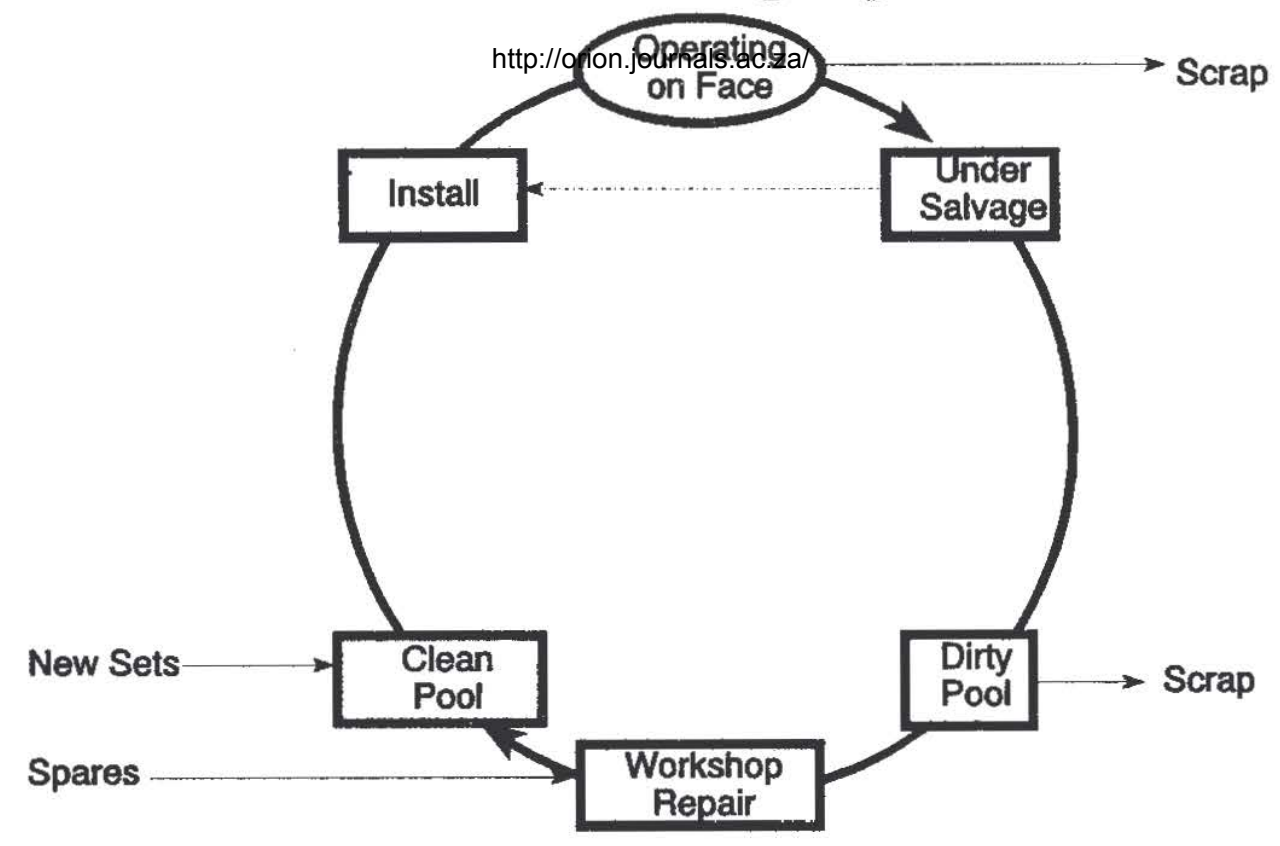

prevents you getting crushed by the several thousand feet of rock above. A small OR team at headquarters were examining all aspects of provisioning and a number of projects had been completed or were underway in several production Areas. This subject area also attracted other groups of specialists particularly from within the mining and purchasing functions.

Because of the importance of the cost of provisioning and indications that $O R$ effort could prove productive, it was proposed that my first task should be to extend the field of enquiry by establishing a project in the general area of powered support provisioning in the North Yorkshire Area. Others engaged in the field described the 'provisioning cycle' to me.

A new set of perhaps 200 powered supports would be specified by Area mining specialists and designed by the manufacturers with a particular face in mind. The supports would be delivered all shining and white to the surface of their designated pit. When the new face had been developed underground, the 200 supports, each weighing up to a tonne, would be transported to the face and installed. Production may then start straight away, or the face may wait until a production team of 
miners had finished working on another face and became available. Production would then start and continue until the face reached the end of the planned extraction or an insurmountable problem is hit such as a large unexpected fault. The production team then moves ht//orioff journals.ac.zal a new face. The supports are recovered, a process known as salvage, and taken to the surface and thence to workshops for repair and preparation for the next designated face.

The statistics for this cycle were reported nationally and were therefore fairly easily accessible. Overall North Yorkshire's percentage utilisation, defined as the number of sets of supports on working faces divided by the total number owned by the Area, was just over $40 \%$. On the face of it a poor utilisation of equipment, certainly lower than most other Areas. My first task was to try and explain this statistic and in the process I would hope to find some aspect that could be improved, thus justifying the cost of $\mathrm{my}$ investigation and establishing $\mathrm{my}$ credibility in the Area.

After a time I had worked out an explanation of the Area's equipment utilisation performance. This clarified certain issues but at the same time unearthed a mystery: a large proportion of the down time was accounted for by supports being salvaged or waiting to be salvaged. This didn't make sense. New supports were being purchased at great expense, while similar sets were lying idle, unused, waiting to be salvaged. To my surprise, despite all the activity being focused on powered supports, no-one had deemed salvage worthy of examination. It is hardly the glamorous part of the business. This was a very long way from the heady stuff of solving societal problems which, as a new OR scientist, I hoped to address. Anyway, I decided this was where I might make an impact and persuaded my sponsors in the Area that I should spend the next 6 months steeping myself in the subject of salvage.

Over the weeks that followed I talked to a lot of people. The question I kept asking was why does it take such a long time to salvage powered supports once the face had finished. I quickly eliminated technical explanations, of which there were many, and discovered that at some pits it was simply a job that was not 
considered critical and could wait until a convenient moment. But why was it not considered important? And why at some pits and not others? I talked to the mine planners who showed me the production plans for the pits. These were in the form of action plans showing bar chtp///orion.journals.ac.zal of face development, face production and yes, there it was, salvage had not been forgotten.

If salvage was in the plan, why was it not being expeditiously carried out? To find the answer, I had to observe what happened in practice when men were deployed to different tasks as they came on shift. This meant going to a pit at 6 in the morning and spending an hour or two with the senior overman in the manpower deployment office. I needed to do this at several pits to get some idea of the variety of ways of deciding priorities on the day. I discovered that the main issue was how to man up all the tasks, faced with high levels of absence which varied greatly from day to day. At one pit they simply overmanned each activity, so that on average it would be about right. At another a group of men were identified as "market men" who were deployed at the last minute into the gaps created by absenteeism. There were often insufficient market men to fill the gaps in the salvage team and on bad days the salvage team was raided to fill gaps in the higher priority production teams. Different attitudes to salvage were observed. Some pits insisted that the finishing production team also salvaged the equipment. Another used salvage as a fallback activity, to be carried out when production or development teams fell idle. Yet another had a specialist salvage team that moved from face to face as they finished.

Up to now I had been asking questions. But which of these methods were rational in terms of the objective and constraints at each pit? I felt a need to understand the logic and perhaps make some calculations. The overall objective of the pit is to get as much coal to the surface as possible and to do it efficiently from an ore body with a given (but only partly understood) geology. In the medium term this meant balancing the production and development activities to keep sufficient faces in operation. In the short term the objective was to fill the shaft, as the shaft was usually the bottleneck. Capacity not used on a shift is lost forever. Quite unexpectedly, at any time in its life, a face could be stopped by a fault or, what is 
called a washout. The men then needed to be rapidly redeployed to other faces to maintain the overall production and keep the shaft full.

\section{http://orion.journals.ac.za/}

The action plans were drawn up to address this uncertainty but were presented simply as a single bar chart with only one path. Everyone knew the outcome would be different but the plans were a convenient fiction. I was interested in the stochastic nature of face finishes, the accuracy of the planners expectations on which the plans were based, and the implications for the mine manager who wanted to keep the shaft filled. I therefore derived a simple model containing some statistical analysis and a rational model of a manager's decisions. With the model it was possible to show that most of the delay in salvaging equipment was actually quite rational, in fact, given the simplifications involved, the fit between the theory and practice was remarkably good.

This result might seem disappointing as it did not indicate a better way of taking decisions: the pit managers were already doing well against the criteria assumed. However, a decision model that closely resembles the way that decisions are actually made gives a reasonable basis for testing out different policies. I turned my attention to finding different ways of affecting the decisions. These included charging the mines artificially inflated hire rates, giving the ownership of the equipment to the mines or using specialist Area based salvage teams. I favoured the latter policy and identified the savings that would result, again by modelling the work to be done, Howard and Ormerod [1].

At this point disaster struck. The sponsor of my work, the Area Chief Engineer, was moved to manage the new Selby coalfield project with the challenge of developing the largest mining complex in the history of the Board. I went to see his successor. He was blunt. He believed in the sanctity of the pit as a management unit, Area salvage teams were out of the question. That was that. I was bitterly disappointed that so much effort, and in my view, good thinking was going to waste. I am sure many of you have suffered a similar fate at some point in you career and can sympathise. 
What has this to do with my theme of strategy? Starting with a typical operational question about the utilisation of equipment, I had found myself drawn into a debate about the management of the pit, the organisation of the Area and the management style. It was not a debate for which I was particularly well equipped. In the end I lacked credibility and was easily brushed aside. I had been asked to look at powered supports, not to question how the Area should be run. I had, however, experienced something very important: operational questions had strategic significance; OR work at the tactical, operational level had implications for strategy development.

I might, of course, have continued down this road, tackling more operational problems, discovering the strategic implications and in time, I hope, becoming more successful at achieving implementation. It was not to be. The next question I was asked to address came from the Area Director himself.

The Area for a number of years had budgeted to achieve an output of 9.2 million tons and indeed had a track record of achieving its budget. The Area Director, who had recently moved into the post, on the advice of his management team, had accepted a budget of 9.2 million tons. It was now some 5 months into the budget year and on the basis of the results to date the projected outcome for the year was 7.5 million tons, a truly disastrous position for the Area in general and the Director personally. It was not clear whether the bad results could be expected to continue and what should be done, if anything, to put them right. The Director wanted an objective opinion from someone not involved.

I followed the same pattern of enquiry as before. Starting with the statistical records and talks with the planners, I visited a number of pits to see what decisions had been made, why and with what consequence. The favoured explanation at the time was that a recent disaster in the Area (the Lofthouse disaster) had had knock on effects on neighbouring pits, causing the shortfall. My investigation showed that this was not the case and pointed instead to changes in technology and extraction strategy. This investigation was clearly strategic in intent and was well received as such. As a consequence I initiated the building of 


\section{8}

a long term area model for budgeting purposes, particularly in the light of the new Selby complex which was planned to produce 10 million tonnes per annum, more than the rest of the area put together. In the course of these endeavours I had moved from operational issues with strategic consequences to engaging in strategic questions directly.

\section{OR TO SUPPORT STRATEGIC PLANNING WITH FACTS AND MODELS}

A year later I found myself in charge of the Strategic Modelling Section for the NCB as a whole. Perhaps I should explain that although the name National Coal Board sounds like some sort of industry association, the NCB was in fact a Government owned nationalised industry, run as a single company. It was one of the largest companies in the UK at the time employing some 300,000 people. Our task in the Strategic Modelling Section was to build models to support the planning and strategic thinking of the Central Planning Unit (CPU) who reported to the Chairman and advised the Board. Several years later I moved across into CPU itself, responsible as its Deputy Director for gathering intelligence, evaluating plans and coordinating the planning processes within the organisation, Ormerod [2]. I continued to sponsor the work of the Strategic Modelling Section and therefore enjoyed 11 years continuous involvement in the building and use of models which supported the planning process. Such continuity is quite unusual.

The NCB strategic model was in fact a collection of models that could, in theory, be connected but seldom were. The models covered the supply of coal, based on the production possibilities included in the mine plans, and the demand for coal derived from models of each market segment. We were looking up to 10 years ahead. As our efforts progressed we extended the models to the year 2000 (ie 20 years ahead) and reached deeper into the energy and economic environment. We also started to model the interaction of supply and demand in what was called the Matching model. The complete suite of models is described in Plackett, et al. [3] and Ormerod and McLeod [4]. I will concentrate on three of them. 


\section{The UK Energy Demand Model}

This model was the mainstay of the ORE Strategic Modelling Unit's effort over the 11 years of my involvement. It tracked the flow of energy from the suppliers of oil, gas, coal and nuclear energy, through the various conversion industries to meet the demands of consumers, industry and commerce. It calculated prices of delivered fuel from assumptions about world oil and gas prices. It estimated how these prices, changes in consumer technology (such as central heating and conservation) and economic activity combined to affect consumption of the different fuels.

One of the reasons that the model was successful was because at its heart there was the electricity generating system, a system that lent itself to modelling. The electricity sub-model contained details of every existing power station in the UK and the building programme for those under construction or planned. The model simulated the system throughout the year based on merit order operation. This required the cost of operating every station to be calculated based on its thermal efficiency, the fuel used and its cost to the system. It also required an estimate of the demand for electricity. In aggregate this demand was derived from price competition models in the domestic, industrial, commercial and transport sectors. The variations in demand through the year, through the week and through the day in half hourly intervals were summarised in a demand duration curve. Stations were then loaded against the demand by merit order, ie order of operating cost. With some judicious tuning, the results were remarkably good and not always intuitive.

The UK Energy Demand Model was central to the medium and long term plans that had to be submitted to the Department of Energy and Treasury. In 1983 the NCB was investigated by the Monopolies and Mergers Commission. They compared our model to others and concluded "We consider the NCB's model is quite sophisticated in forecasting demand for coal ...", Monopolies and Mergers Commission [5]. In the circumstances praise indeed. The model integrated large amounts of information that we either had available or could obtain. In the early 
eighties a similar need was felt to integrate the increasing amount of information that was becoming available on world steam coal trade.

http://orion.journals.ac.zal

The World Steam Coal Supply Model

To model the trade in steam coal we needed to obtain estimates of the future supply availability from the major coal exporting regions (the US, South Africa and Australia), estimates of demand growth in the major importing areas (Western Europe, Japan and the Pacific Rim) and the costs of transportation. The costs of transportation we captured in a shipping model.

\section{Shipping Cost Model}

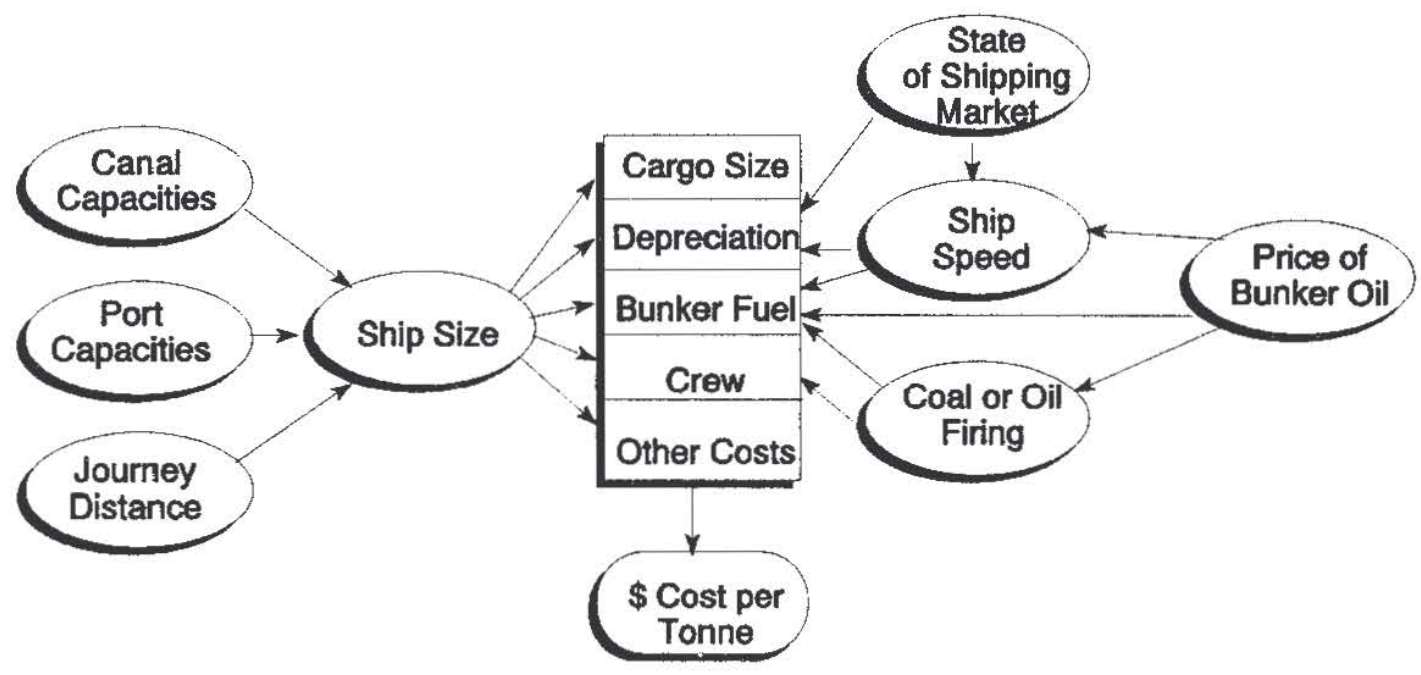

The model contains engineering calculations which are quite straight forward. They allow the user to recognise that, for instance, in a particular scenario world shipping capacity may be in surplus. In this case slow steaming may be preferred to reduce bunker costs and ship owners will only be able to recover their operating costs. When the shipping market is in balance, full costs will be recovered in the rates, including a capital charge. Using the costs derived from this model the trade flows could be calculated from the supply and demand estimates for any year.

Intelligence across a whole range of subjects, which had previously been difficult to gauge, could now be given significance. For example, if a Scandinavian country announced they were applying restrictions to the import of South African Coal, the 
consequences could immediately be worked out. This model played a significant role in the evidence we gave to an enquiry in the mid eighties into the case for building Sizewell, the first PWR nuclear power station in the UK. http://orion.journals.ac.za/

The continuous development of the full suite of madels over a period of 15 years or more provided a unique capability. It helped the Central Planning Unit match the ever increasing variety of the UK energy policy debate with only a handful of strategists in comparison with the hundreds employed in the gas, nuclear and electricity industries. The models described are examples of model building to support strategic planning. This is the second in my list of roles for OR in strategy development.

\section{THE APPRAISAL OF INVESTMENT DECISIONS}

The models described above are designed to encourage a greater degree of rationality in decision making by making the sums easier, the facts more available and the logic more accessible. They are tools to be used to support decision making in what.....if mode. They do not in themselves address the question of what the investment decisions ought to be in the light of the facts; they do not help in evaluating the logic of the decision directly. Over the years OR has developed or borrowed a whole range of approaches and techniques relevant to investment decisions and in the NCB we made use of them. I want to describe a particular problem that faced us.

In the mid eighties it became apparent that we had to rethink the way that we carried out our investment appraisal. We were faced with conundrums. We had ever growing stockpiles of coal. Some were of the view that coal should therefore be given zero value in our evaluations! Others pointed out that historically stocks were always lifted in the end and coal should be valued at the price at which we were selling to the electricity industry, about $f 40$ /tonne in those days. We were also worried about the increasing availability of imported coal at, let us say, $£ 30 /$ tonne and how demand for coal would develop in the light of various scenario assumptions. These assumptions alone could make an investment sink or swim. 
There was also debate about the discount rate that should be applied to nationalised industry investment; and so it went on.

My feeling was that we were strugiggling to reconcile opportunity costs through time. What we needed was a linear program to do the calculations for us. It turned out to be very simple to build it up a step at a time. In any particular year we could define activities such as mining coal, delivering coal, investing in new capacity, exporting and importing coal which were constrained by capacities and the need to meet market demand. The resulting formulation for one year is illustrated below.

\section{UK Coal Supply/Demand Matching}

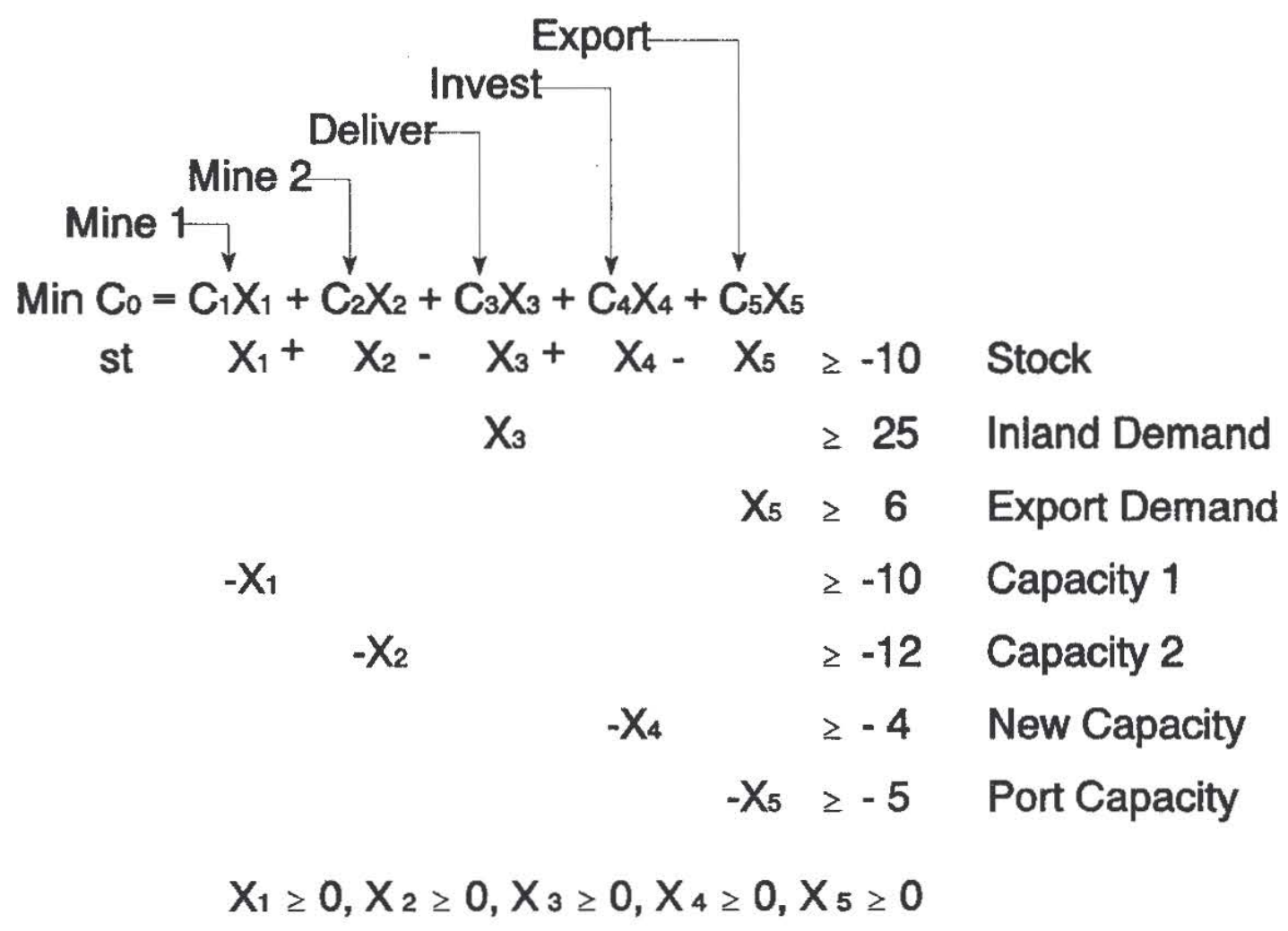

Each year is connected to the next by the end of year stocks, capacities and reserves. The financial results are aggregated up using a discount structure. The resulting multi-time period linear programming structure is shown below. We were now able to answer our questions about the appropriate value of coal for investment purposes taking into account all the factors that we thought important. 
As you would guess the answer we were seeking lay between the extremes of nought and $\mathrm{f} 40 /$ tonne. We now had a specific answer for a given set of scenario assumptions. The answer was different for each year and led to something called the $f 15 / 20$ rule for valuing coal.

\section{UK Coal Supply/Demand Matching}

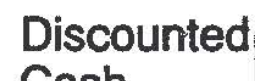

Cash

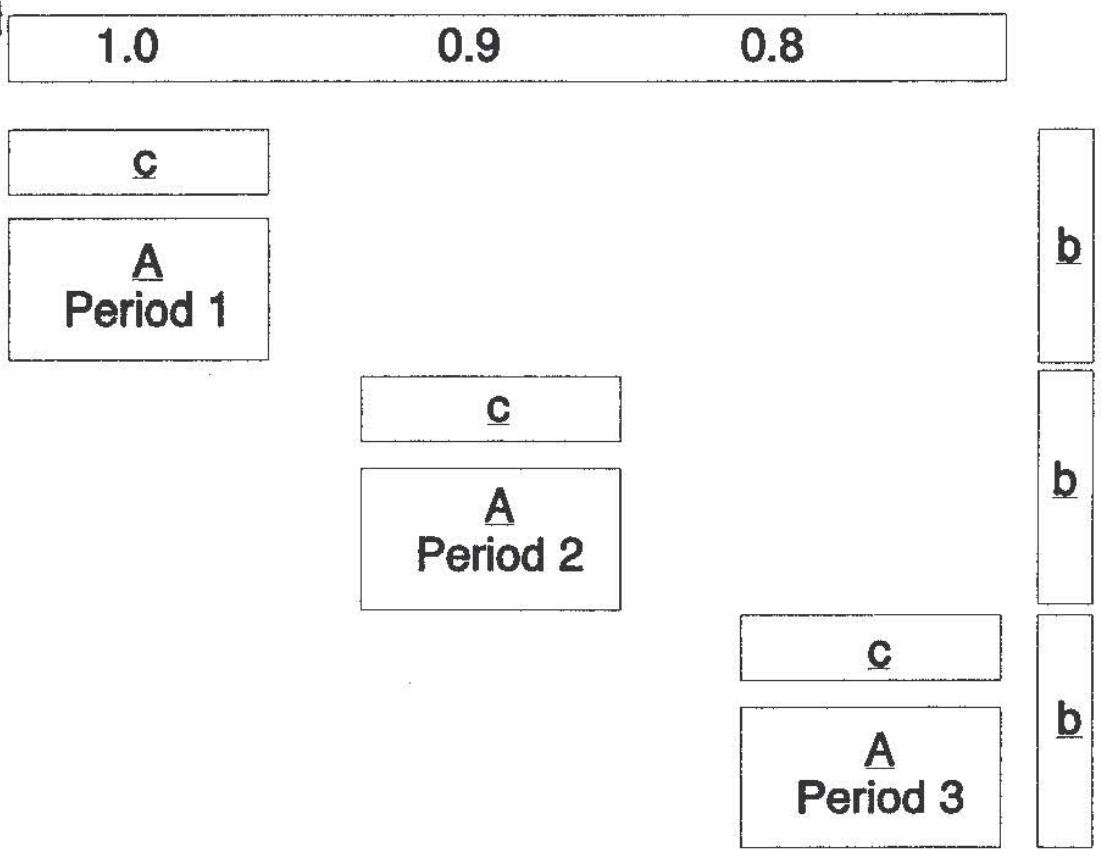

\section{Stocks/Capacities/Reserves}

The model once built could be used to address a whole range of issues and became a vital part of our analytical armoury. This is an example of the use of OR to help with the analysis of investment decisions. This is the third of my categories.

\section{OR AS A METHODOLOGY FOR THE PROCESS OF STRATEGY DEVELOPMENT}

After 13 years of working for the NCB, subsequently known as British Coal, I left to seek my fortune in consultancy. I decided to specialise in something completely different, IS strategy. This was not quite as surprising as it sounds, as I had spent my last two years at British Coal addressing the issue of IT management and strategy. In consultancy I worked on a number of large IS strategy exercises for 
UK, foreign and international companies. Not least I worked for 6 months with Volkskas in Pretoria.

To my surprise my most useful asset in this new endeavour were my investigatory craft skills developed as an investigator in the coalfields all those years ago. I also discovered that my colleagues in consultancy, who were experts in developing business strategy, used methods which seemed almost identical to the process of enquiry that I had used as an OR scientist.

Earlier I described the process of doing OR as I had experienced it. The task was to tackle the practical problem of increasing equipment utilisation. The process of enquiry was to gather facts, observe and ask questions, building up an understanding of the problem and its context. In the process some statistical estimations were made and models were built to provide insight and to calculate consequences of changes in policy ie to provide a basis for experimentation. It was necessary to widen the focus of the enquiry to understand the problem. The enquiry had to take into account different points of view and crossed departmental boundaries. This practical approach seemed to emerge out of a sense of what was needed, no doubt some understanding of how more experienced colleagues tackled problems and a notion that the investigation should be rational and objective. In this context the idea of an explicit model was attractive but by no means required. We were called scientists but $\mid$ do not recall anyone explicitly referring to the scientific method. However, I do not doubt that our sense of what was right to do was informed by our scientific culture.

In my consultancy work I have increasingly drawn on the newer, 'soft' OR approaches such as cognitive mapping, soft systems methodology, and strategic choice, all of which are described with worked examples and references in Rosenhead [6]. Each approach is a way of intervening in complex or messy situations to generate understanding, improvements and agreement to act. In the case of cognitive mapping, the way that actors in the situation think about the choices and varibles are captured in maps in the form of bi-polar concepts and the relationship between them. The maps of individuals are then compared and 
contrasted to produce a merged map and possible changes in direction are explored. The result could be a new strategic direction. in soft systems methodology systems, considered as wholes, are identified and defined from the viewpoint of different actors. A conceptual model of the necessary activities associated with the system is compared with the actual situation to identify systemically desirable and culturally feasible improvements. The result is an agenda of changes for further debate and analysis. In strategic choice options are identified and compared using criteria developed by the participants. The approach is particularly good at handling uncertainty. The result is an agreed commitment package consisting of decisions to be taken now, contingency plans, decisions to be taken later and exploratory activities to be carried out in the mean time.

These approaches draw on the social sciences, putting greater emphasis on understanding peoples perceptions than establishing scientific facts. The academic language of the advocates of these techniques can be off-putting, but they do articulate processes for getting managers involved. Processes that are easily recognised by experienced $O R$ practitioners as close to practice. I find these new approaches of great value in a wide variety of circumstances. Taken together, the traditional approach of OR and the new 'Soft' approaches, provide a powerful combination to guide the process of strategy development. I do not know, and this may surprise you, of a profession better placed to play this role. Facilitating the process of strategy development is my fourth category.

\section{THE ROLE OF OR IN SOCIAL ISSUES}

There is no doubt that $\mathrm{OR}$ can and does have a role to play in addressing societal issues. How should health services be organised? How can environmental issues be addressed? How does transportation policy interact with urban development? But in South Africa today undoubtedly the biggest societal issue is the political future of your country and its consequences. At one level you are all ordinary citizens. At another, as trained OR investigators, you have an unusual capacity to grasp the logic in situations. Individually only a few of you will have access to the corridors of power, wherever they may be in this fluid situation. Is there anything you can do collectively? Is there any help you can give to people who are having 
to face complex questions for the first time? The answer must be yes potentially, but can the potential be realised in any way? These are not easy issues but they are strategic and relevant and I have never found South Africans slow to confront difficult issues. I am looking forward to hearing both formally and informally what you propose. Analysing societal issues is my final category in my list of roles for OR in strategy development. It is by no means the least important but it is possibly the most difficult. It is the one area where OR scientists can have their own views and prejudices. Where they can say what ought to happen because they think it is right.

\section{CONCLUSIONS}

Five roles have been identified for OR in strategy development. Each, I believe, highly significant.

- $\quad$ Research into operations with strategic implications

- Establishing facts and models to support the strategic planning process

- $\quad$ Analytical support for investment decisions

- $\quad$ Facilitating the strategy development process

- Participating in the analysis of socially important issues.

I do not think we, as OR scientists, have the right to demand a role in strategy but we do have the skills, aptitudes and methods to allow us to play a useful role. The key is confidence. There is no OR solution to strategic questions. But there is an array of OR approaches to help shape and resolve the issues. I would place particular emphasis on the process of OR; the process of understanding the context, constructing the logic, identifying questions of fact, gathering evidence, developing options and evaluating them; the process of identifying relevant actors, their interests and their involvement in the project; the process of decision making and implementation; the process of exploration, learning and discovery that makes the conduct of OR exciting; the process of designing and improving. We all need to get into the habit of articulating our process of inquiry, however obvious we think it is. 
The aim of my paper is to counterbalance the view that $O R$ is a narrow, mathematical discipline suitable only for well-defined, operational issues. To be invited by clients to address the wider, more strategic issues the OR scientist must continuously make the case that itpilorion.journals.aczal to examine the wider picture, consider different points of view and question the assumptions behind the initial terms of reference. We must all get into the habit of identifying the strategic issues, however mundane our remit.

I hope what I have said has raised some questions in your minds. I also hope that by now you agree that strategic issues are important for OR scientists and there is rather a lot to do. Of course, the heart of this conference lies in the technical sessions which follow over the next few days. There you will be presenting a great variety of problems and the solutions you have derived. Only a few papers will be specifically about strategy and even fewer will articulate the practical OR skills that you brought to bear. But I think it would help enliven our sessions if we addressed four questions:

How did you go about understanding the problem?

What did you learn about the process of doing OR?

What is the strategic implication of what you discovered?

Is there a social dimension to your project?

Conference addresses are quickly forgotten in the interest and excitement generated by the sessions that follow. I will ask you only to take away these four questions.

\section{REFERENCES}

[1] J.V. HOWARD and R.J. ORMEROD, Models of Colliery Organisational Systems, an invited paper at the Royal statistical Society Industrial Application Section and Research Conference, UMIST, (1977).

[2] R.J. ORMEROD, Corporate Planning and the Use of Operational Research at the National Coal Board: a Personal View, Journal of the Operational Research Society, 34, 461-467, (1983). 
[3] M.W. PLACKETT, R.J. ORMEROD and F. TOFT, The National Coal Board Strategic Model, European Journal of Operational Research, 10 (4) (1982).

[4] R.J. ORMEROD and J. MCLEOD, The Development and Use of the NCB Strategic Model, The Statistician, 33, 35-49, (1983).

[5] The Monopolies and Mergers Commission, The National Coal Board: A Report on the Efficiency and Costs in the Development, Production and Supply of Coal by the NCB, Cmnd. 8920, HMSO, London (1983).

[6] J. ROSENHEAD, Rational Analysis for a Problematic World, Wiley, Chichester (1989). 